\title{
SUBPHRENIC SUPPURATION AND ITS COMPLICATIONS
}

\author{
H. C. NohL, M.A., D.M., F.R.C.S. \\ Thoracic Surgeon, Harefield Hospital, Hillingdon Hospital and West Middlesex Hospital
}

THE diagnosis of subphrenic abscesses can be notoriously difficult. This fact is well expressed by the well known aphorism: 'Pus somewhere, pus nowhere else, pus under the diaphragm'. Even more puzzling can be the features when complications, which occur relatively frequently, dominate the clinical picture. The situation of the subphrenic spaces, hidden under the rigid concavity of the ribs and therefore inaccessible to palpation, is mainly responsible for the paucity of obvious clinical signs. The purpose of this article is to stress the not so infrequent bizarre presentation of subphrenic suppuration and draw the clinician's attention to this hidden area.

\section{Anatomy}

A knowledge of the anatomy of the subphrenic spaces is essential in the management of these cases. The subphrenic region is generally considered to lie between the diaphragm above and the transverse colon and mesocolon below. These spaces have been variously described (Barnard, 1908; Mitchell, 1940; Harley, 1949; Wooler, 1956), but Harley's description is both clear and practical. (For a full understanding of the anatomical facts see Figs. I to 4.)

Both on the right and the left there are spaces above the liver (supra-hepatic) and below it (infra-hepatic). The supra-hepatic space on the right is separated from that on the left by the falciform ligament, while the infra-hepatic compartments are divided into right and left by the ligamentum teres and ligamentum venosum. Altogether there are five intraperitoneal and two extraperitoneal spaces.

The more detailed description of the subdiaphragmatic spaces as given by Harley are as follows:

\section{The Right Subphrenic Spaces}

\section{INTRAPERITONEAL}

(i) The right supra-hepatic space lies between the diaphragm and the liver and is bounded posteriorly by the upper layers of the coronary and the right triangular ligaments. These separate it from the bare area of the liver. It is important to stress that this is a very large space, reaching from the anterior abdominal wall right back to the posterior aspect of the liver. Abscesses can therefore be situated anteriorly or posteriorly in this space. (ii) The right infra-hepatic space is synonymous wh Rutherford Morrison's kidney pouch. Its upper border posteriorly is formed by the lower layer of t⿱一𫝀e coronary ligament. In front of it lies the liver and the gallbladder, while below it communicates with the right paracolic gutter.

\section{EXTRAPERITONEAL}

This space lies between the two layers of the coronagy ligament and therefore is in contact with the bare area of the liver.

\section{The Left Subphrenic Spaces}

\section{INTRAPERITONEAL}

(i) The left supra-hepatic space lies above the left lobe of the liver and is limited behind by the upper \&aver of the left triangular ligament, while in front, ove the edge of the liver, it communicates with the left antegrigr infra-hepatic space.

(ii) The left anterior infra-hepatic space is situatêd below the left lobe of the liver and in front of the lesser omentum and stomach. Wooler (1956) points out that the left lobe of the liver and the left triangular ligamest lie near the centre of the abdomen and that there is therefore a wide communication between the supra- a the infra-hepatic spaces.

(ii) The posterior infra-hepatic space comprises lesser sac.

\section{Extraperitoneal}

This space constitutes the areolar tissue around upper pole of the left kidney and suprarenal and the bare area of the œsophagus.

In conclusion it must be realized that all these spages communicate with each other (Mitchell, 1940) and this explains the not infrequent occurrence of multiple space infection.

\section{Etiology}

In $90 \%$ of cases subphrenic suppuration is ' secondary' to infection elsewhere in the abdominal cavity (Harley). Perforated peptic ulcers, appendicitis, abdominal operations and thoracoabdominal warwounds in that order account over $70 \%$ of cases in that author's series. In Windsor's (1955) roo patients, diseases of th $\mathrm{e}$ stomach and duodenum also head the list $(48 \%)$, followed by appendicitis $(23 \%)$, while liver and biliary diseases come a close third $(22 \%)$. In the older series, e.g. Barnard (1908) and Ochsner apd DeBakey (1938), appendicitis is the predominast 



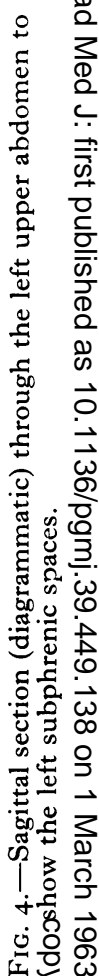

흑이
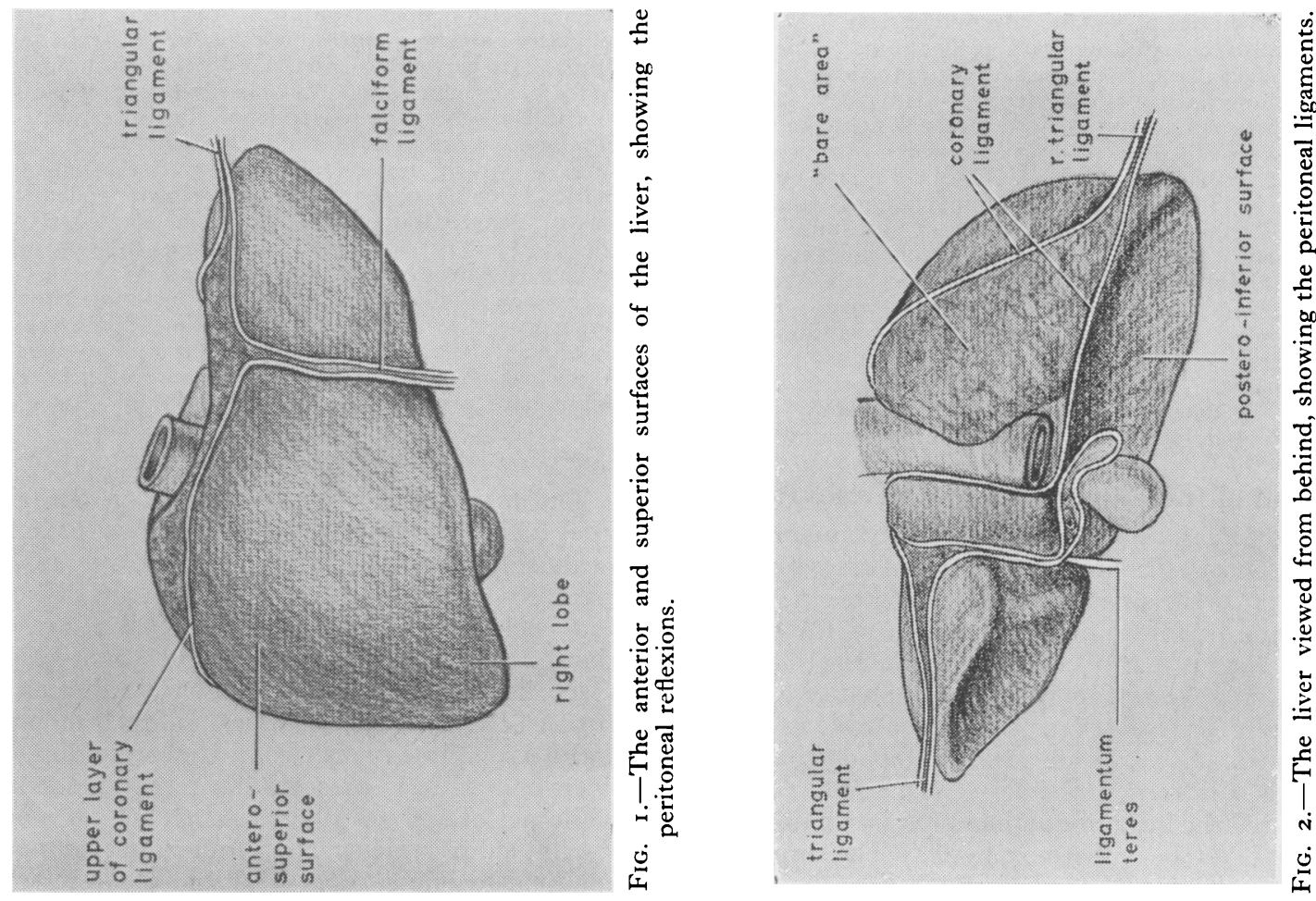
cause of subphrenic suppuration. The reason for the change in the incidence is probably that upper abdominal surgery is now done far more frequently than in former days. Only occasionally no detectable cause can be found and these are then presumed to be 'primary' bloodborne infections. A number of extraperitoneal abscesses are considered to be primary, but the majority on the right side originate from infections in the liver and this is especially so in tropical countries where amœbiasis and hydatid disease are common.

\section{Bacteriology}

The most common infecting organisms are escherichia coli, anaerobic streptococci and staphylococcus pyogenes. In about half of the cases the infection is a mixed one. On rare occasions an actinomycotic infection may be the underlying cause. The recognition of this type of infection is important as only prolonged penicillin therapy will prevent a protracted illness. In patients who have lived in tropical countries entamoeba histolytica or echinococcus may be the causative organism.

The following case illustrates how a history of residence abroad should bring this diagnosis to one's mind:

Case No. 1. L. C., aged 35, a Hindu unable to speak English. Complained of pain in the right chest, aggravated by a recent cough for five days. There was also difficulty in breathing. On examination he was found to be an ill-looking, dyspnœic man. Temperature $101^{\circ} \mathrm{F}$., respiration rate 30 per min. There was diminished percussion note and air entry over the right lower lung with tenderness on pressure over 12th rib. The chest radiograph showed a raised right diaphragm with a small pleural effusion, which on aspiration yielded straw-coloured fluid. W.B.C. 23,200/cu. mm., E.S.R. $53 \mathrm{~mm}$./hr. A subphrenic abscess was diagnosed. At operation a liver abscess was found in the bare area which was at the point of bursting. This was drained and contained typical pus like 'anchovy sauce' which revealed entamaeba histolytica. With a full course of emetine the recovery was quick and complete.

Comment. This was not a true subphrenic abscess and if the diagnosis had been made correctly chemotherapy alone would have been the right treatment.

\section{Spread of Infection to the Subphrenic Region}

The way the subphrenic spaces become infected is still uncertain. In the majority of cases $(64.9 \%)$ there is direct spread from a neighbouring focus (Harley). More difficult to explain is the spread from distant parts of the abdomen: that this occurs via the retroperitoneal lymphatics as suggested by Truesdale (1933) is improbable as extraperitoneal abscesses are rare. Infection therefore spreads intra-peritoneally. Overholt (I93I) measured the intra-abdominal pressure in dogs and found it to be subatmospheric. The pressures varied with the phases of respiration, becoming more negative especially during inspiration. Overholt and Donches (1935) believe that in the upright position the negative pressure in the subphrenic region is greater than in the pelvis and that this results in suction of infected fluid upwards into the subphrenic spaces. Mitchell (1940) investigated the spread of intraperitoneal effusions by injecting barium emulsion into the abdomifal cavity of stillborn infants. It is doubtful wheth\&r his conclusions, which differ very much from those of other authors, are valid as the conditions of the experiments were far from physiological. Gravity is another factor which will determine the colleetion of fluid in these spaces, as they form the lowest area in the abdominal cavity with patient in the recumbent position. Spaldiăg (1946) makes the point that subphrenic abscesifss are known to follow appendicectomy but hardhy ever complicate conservatively treated cases. He maintains that the normal upward movement iff fluid into the subphrenic spaces is accelerated by the presence of a pneumoperitoneum whioh alters the intra-abdominal pressure differences. It is far more likely that the pneumoperitoneur opens up the subphrenic spaces. The following case illustrates the harmful effects of a pneumaperitoneum.

Case No. 2. W. J., a 60-year-old housewife, treict since 1953 for pulmonary tuberculosis with ज्ञnfituberculous chemotherapy and phrenic crush a fd pneumoperitoneum. Sputum in 1961 was still posituve on culture and resistant to most of the anti-tuberculofs drugs. In November 1961 she developed appendiciôs and a gangrenous appendix was removed; pelvic perftonitis was noted at the time of the operation. Sfe developed a right supra-hepatic subphrenic abscess (Fig. 5) which was treated conservatively with antibiotics from November 1961 to February 1962. Th was ultimately drained after it had perforated into the chest. The patient died, drowning in pus whigh spilled over into both bronchial trees.

Comment. The presence of the pneumoperitoneuis predisposed to subphrenic infection. The abscess should have been drained when it became established. A tracheostomy at the time of drainage of the abscess might have saved the patient.

\section{Location of Subphrenic Abscesses}

The majority of abscesses occur on the right side, while in a quarter of the cases recorded by various authors the left-sided compartments were involved (Ochsner and DeBakey, 1938; Neuho्ff and Schlossmann, I942; Harley, 1955). Ip about half of the cases the right supra-hepatic space is infected (Harley, I955; Wetterfors, 1959). Right-sided abscesses follow predomi antly upon infections from the appendix, the liver and biliary passages and the duodenum; while perforated gastric ulcers involve more ofteृg the left subphrenic spaces. Infection may not Re confined to one space. Multiple space infection 


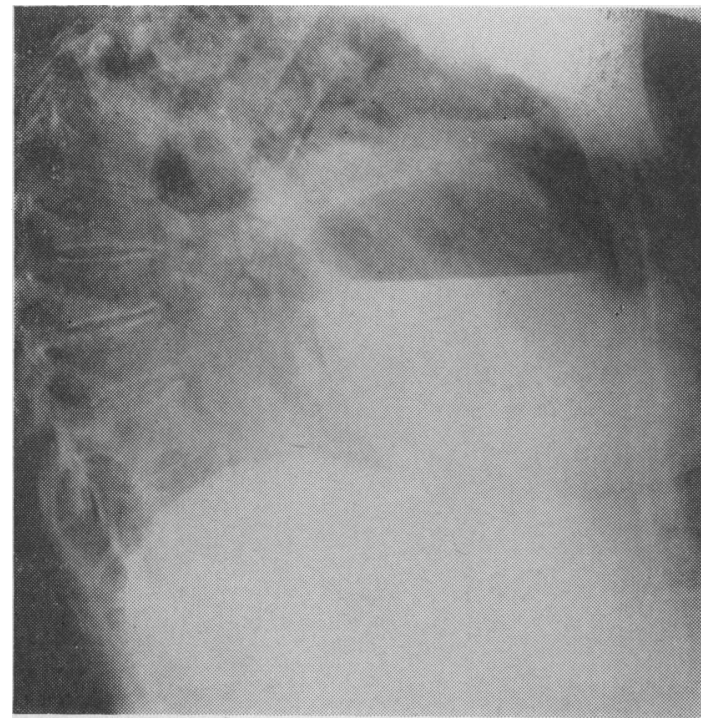

FIG. 5.-Case no. 2. Lateral radiograph showing a large anteriorly situated right supra-hepatic abscess, occurring in a patient previously treated with a pneumo-peritoneum. Note the tuberculous cavity in the apical segment of the right lower lobe.

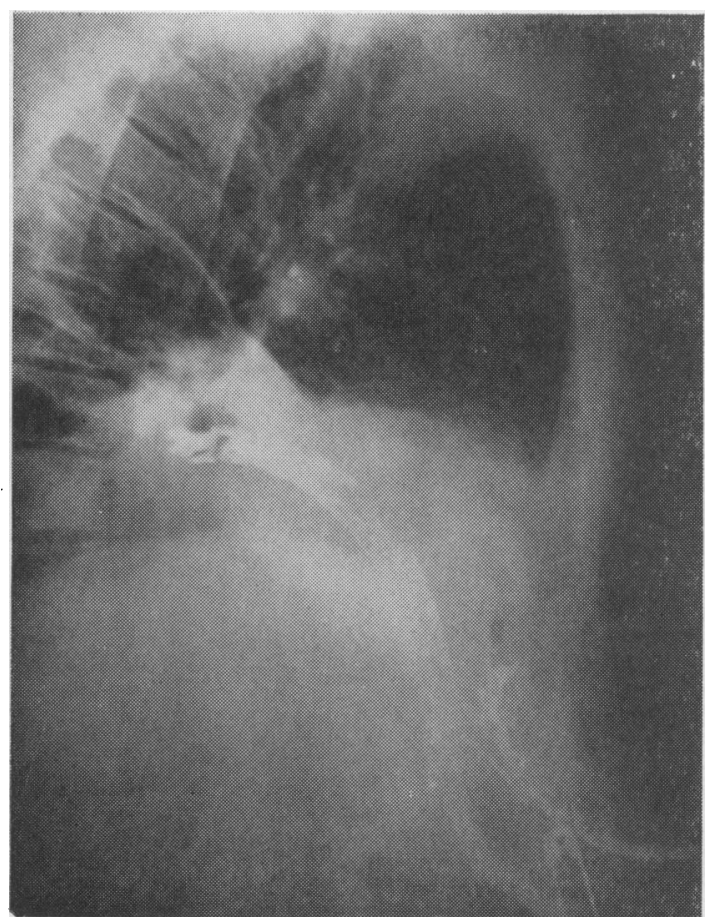

Frg. 6.-Case no. 3. Sinogram of an anteriorly situated supra-hepatic abscess.

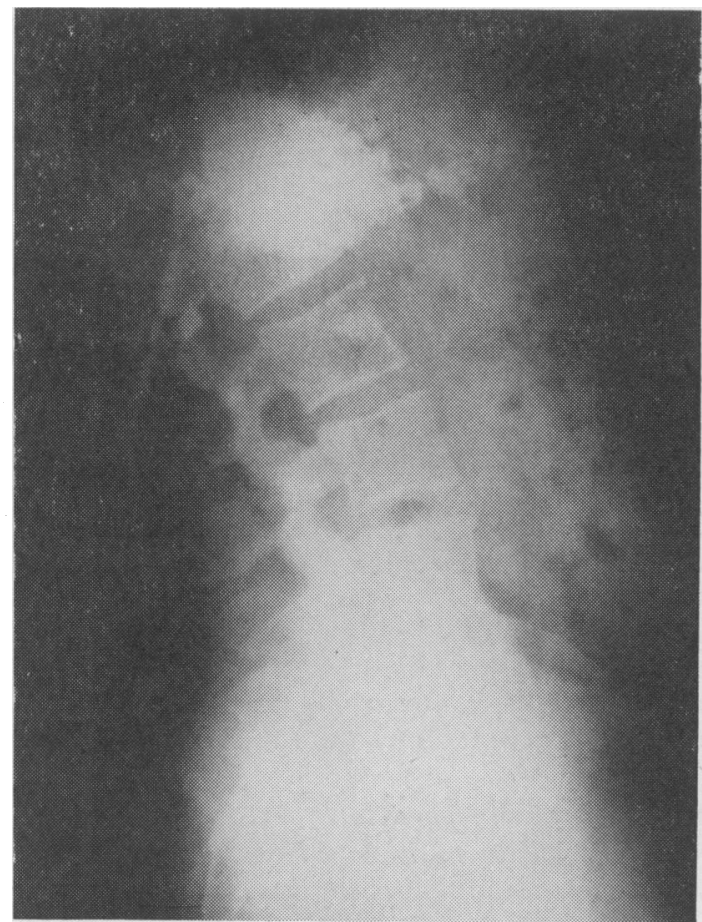

FIG. 7.-Case no. 3. Sinogram of a right infra-hepatic abscess, drained posteriorly one year after drainage of the anteriorly situated supra-hepatic abscess.

occurs in about a quarter of the cases (Windsor, 1955; Wetterfors, 1959) and carries an approximate mortality of $50 \%$ (Harley, 1955; Windsor, 1955). Even worse is the prognosis of bilateral subphrenic abscesses, which occur in about one in ten cases. Windsor had five patients with bilateral abscesses and none survived, while Harley records a mortality of over $80 \%$. It is therefore most important to have the possibility of a multiple space infection or even bilateral subphrenic abscesses in one's mind. The following case illustrates well how failure to recognize a multiple space infection resulted in prolonged morbidity.

Case No. 3. K. W., aged 32, experienced a dull ache in the right lower chest associated with fever six weeks prior to admission. The pain became progressively more severe and ultimately became localized in the right hypochondrium but also radiated to the tip of the right shoulder. On examination there was a diminished percussion note and air entry over the right lower chest, while palpation" of the abdomen elicited tenderness in the right hypochondrium. Chest radiograph: Partial right lower lobe atelectatis with a small effusion and a raised right diaphragm. W.B.C. 19,000/cu. mm. An anteriorly situated right suprahepatic subphrenic abscess was drained (Fig. 6). The patient was discharged fit and well, except that the 
diaphragm remained slightly raised. Twelve months later he began to complain of the same pain. On examination he was found to be tender in the right lumbar region and his W.B.C. was $15,800 / \mathrm{cu}$. $\mathrm{mm}$. A right infra-hepatic subphrenic abscess was drained posteriorly on this second occasion (Fig. 7).

Comment. This patient had a multiple space infection which was not realized on the first admission, one space only being drained.

\section{Complications}

Serious complications can and frequently do occur in the abdomen or chest, or both, as a result of subphrenic suppuration. Not only is the incidence of such complications as high as $60 \%$, but they also carry the mortality of $50 \%$. Delay in the institution of effective treatment is largely responsible for the high incidence of complications. Wetterfors (1959) denies that the time factor plays a part. It is, however, well known that any long-standing abscess has a tendency to spread and burst into neighbouring structures and this applies even more so to subphrenic abscesses.

\section{Intrathoracic Complications}

The majority of these follow infection of the supra-hepatic spaces. Simple serous effusions are common. Wetterfors believes that pleurisy occurs at a very early stage and noted radiologically a pleural effusion in $89 \%$ of his ror patients. More serious intrathoracic complications occur in nearly half of the cases. Among these empyema, either due to infection of an effusion or due to actual perforation of the diaphragm, heads the list. Lung infection in the form of atelectasis, abscess or suppurative pneumonitis is not infrequent. A subphrenic abscess may in fact also be coughed up. The development of such a bronchial fistula paradoxically reduces the mortality of subphrenic abscess (Harley, 1955), although there is a definite risk, as illustrated by Case No. 2, of drowning when the pus spills into the bronchial tree (Gullickson and Smith, 1956). Another particularly fatal complication is suppurative pericarditis. Harley records four cases all of whom died. In view of the insidious nature of these abscesses, the diagnosis may be very difficult, especially when the symptomatology is entirely confined to the chest.

The following case reports illustrate some of the points mentioned above.

Case No. 4. A. M., aged 40, had an anterior gastric perforation which was treated unsuccessfully by gastric suction and intravenous administration of fluids for the first 24 hours. A laparotomy, with suture of the perforation, was then carried out. Peritonitis was present. The patient recovered from this and was discharged from hospital. Three months later he was readmitted with a history of recent fever, purulent sputum and dyspnca, On examination he was toxic and very



FIG. 8.-Case no. 4. Sinogram of a right anterofpy situated supra-hepatic abscess, which demonsted a small perforation of the diaphragm, caus posterior empyema.

dyspnœic. There were signs suggesting fluid in right lower chest. The previous laparotomy wou $\overrightarrow{\mathrm{B}} \mathrm{d}$ had a sinus which was discharging pus. Chest radisgraph: There was air and fluid in the right chest, the diaphragm was raised and there was some consolidation in the right midzone. Aspiration of the chest confirmed the presence of an empyema. Drainage of the empyema was carried out under local anæsthesia. $3 \mathrm{~A}$ sinogram through the abdominal sinus revealed that the anterior supra-hepatic abscess communicated with the posteriorly situated empyema space via a smiall perforation in the diaphragm (Fig. 8). The subphreqic abscess was then drained through a right anterior ext serous approach. The patient recovered rapidly afger this.

Comment. The abscess perforated the diaphratm within three months. It should be noted that $\mathrm{fin}$ empyema must always be drained independently from the subphrenic abscess.

Case No. 5. G. T., aged 65 , gave a history of $\stackrel{N}{N} 8$ months of shortness of breath, a transient pleufral effusion 14 months prior to admission, and a se weeks' history of recurrent hæmoptysis. There was a past history of urinary calculi. On admission the्षre were no abnormal physical signs. Chest radiograph: Shadow in the basal segments of the left lower lobe, which was further confirmed by tomography (Fig. D্ A penetrating film of the abdomen showed a staghơn calculus in the left kidney. Bronchoscopy and sput cytology were negative. He was treated for one mo th with antibiotics which caused no resolution of the left 


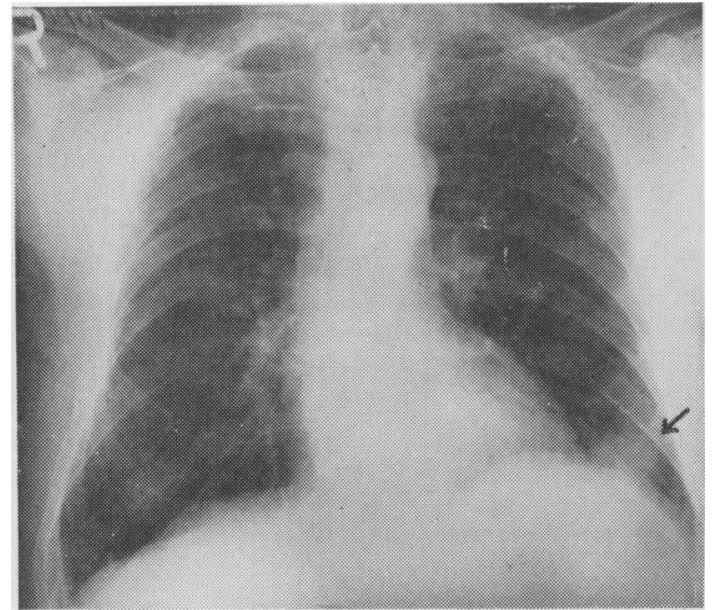

FIG. 9.-Case no. 5. Radiograph showing left basal shadow (arrow) and left raised diaphragm.

basal shadow nor did the hæmoptyses stop. As the possibility of carcinoma of the lung was likely, a left thoracotomy was advised. At operation a softish mass was palpable in the basal segments and these were firmly bound by adhesions to the diaphragm. A portion of the diaphragm was excised and pus was found welling up from below. At a later date a left nephrectomy was carried out for a calculous pyonephrosis which had caused a left extra-peritoneal subphrenic abscess.

Comment. Although the existence of a staghorn calculus was known, a connection between this, the lung shadow and the recurrent hæmoptyses was not suspected.

Case No. 6. Dr. J. M., aged 52, had a cholecystectomy in November 1954, at which some difficulty was experienced during exploration of the common bile duct. Biliary peritonitis followed. In January 1955 a right anterior supra-hepatic subphrenic abscess was drained. July I955: Severe obstructive jaundice. August 1955: The right supra-hepatic space was drained again. September 1955: Signs of cardiac tamponade due to a pericardial effusion developed. The patient had a raised jugular venous pressure, œdema of the legs, and a raised pulse rate (I 18 per min.) with poor volume and distant heart sounds. Radiograph: Large heart shadow; pneumonic infiltration at both lung bases. ECG: Large $P$ waves, low voltage QRS complexes and flat or inverted $T$ waves in most of the leads. The diagnosis of suppurative pericarditis was made and the pericardium was drained and irrigated. A sinogram (Fig. Io) through the previous subphrenic drainage site confirmed the communcation between the abscess and the pericardium. After improvement in the general condition of the patient further exploration revealed a right supra-hepatic and a left anterior infrahepatic abscess. Ultimately after another attack of obstructive jaundice, the common bile duct was reexplored and was found packed with gall-stones, which were removed. The patient made a complete recovery.

Comment. In this case not only was the presence of a multiple space infection overlooked, but also the right anterior supra-hepatic abscess was inadequately drained. The perforation of the abscess into the pericardium

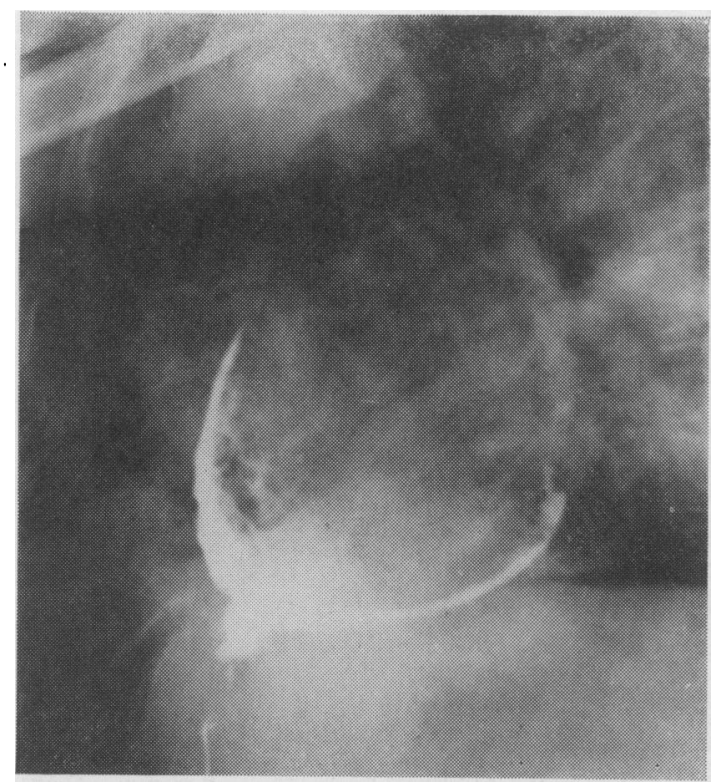

FIG. 10.- Sinogram of previously drained right suprahepatic abscess demonstrates perforation into the pericardium.

resulted in cardiac tamponade; in this case this was recognized early and appropriate steps taken.

\section{Abdominal Complications}

These occurred in approximately a third of Harley's cases. The most commonly met with were simple wound breakdown, generalized peritonitis, localized intraperitoneal abscess elsewhere, fæcal fistula and liver abscesses. These latter may be primary liver abscesses, e.g. amœbic, or secondary to rupture of the subphrenic abscess into the liver, or may be the result of portal pyelephlebitis or suppurative cholangitis. This association of liver abscess with subphrenic suppuration is a particularly dangerous one, as it carries a mortality of $76.2 \%$ (Harley). Another complication which the author has seen on two occasions is septic infarction of the spleen, necessitating splenectomy. Occasionally rupture of a subphrenic abscess to the exterior takes place. This happened in the following case:

Case No. 7. F. M., aged 77, gave a history of vomiting for two weeks, four months prior to admission. He stayed in bed for nine weeks. For the last eight weeks he had swollen legs, which his general practitioner diagnosed as cardiac in origin. Two weeks prior to admission a purulent discharge from the umbilicus was noticed. On examination he looked pale but otherwise well. Temperature $100^{\circ} \mathrm{F}$. There were no abnormal physical signs in any of the systems. Hæmoglobin $58 \%$, W.B.C. $22,000 / \mathrm{cu}$. mm., $81 \%$ were polymorphs. A probe introduced through the discharging sinus at 


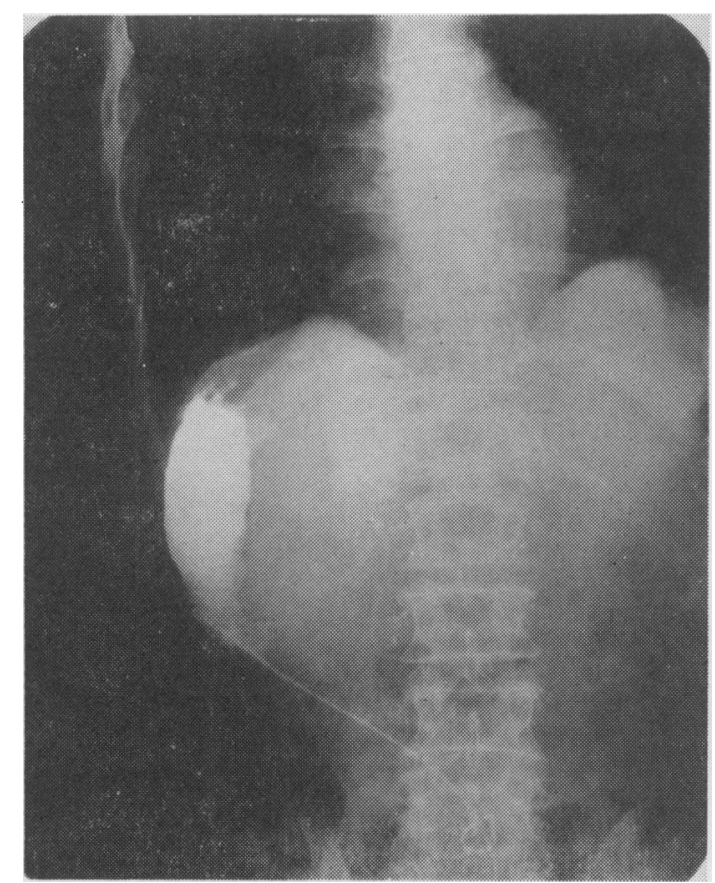

Fig. I I.-Case no. 7. A ureteric catheter introduced through a sinus at the umbilicus (indicated by metal clip) found its way to an infra-hepatic abscess.

the umbilicus went deeply into the abdomen. Therefore a ureteric catheter was passed up the sinus and radio-opaque material injected (Fig. I I ). This revealed a subphrenic abscess. When this was drained, the discharge of pus from the umbilicus ceased.

Comment. This illustrates well the insidious onset of these abscesses. This abscess must have tracked down in the falciform ligament.

\section{Clinical Features}

The onset may be typical, the patient failing to recover satisfactorily from an operation for some acute abdominal condition or following a procedure such as partial gastrectomy. On the other hand the onset is quite frequently insidious, the subphrenic abscess not becoming evident for months. Russell (1929) for instance, reported three cases in which the time interval was seven months, one year and seven years after the original illness. The general symptoms are those of toxæmia, e.g. malaise, anorexia, fever, rigors and nightsweats, while the blood picture frequently shows an anæmia with, usually, a high white cell count. Leucocytosis may, however, be absent and one has the impression that in recent years this may be due to the masking effect of antibiotics. The most common local symptom is pain, which is felt on the side of the abscess, being confined either to the upper abdomen or referred to the chest, when it is usually pleural in type Pain may also be experienced in the shoulder an this is then due to phrenic irritation by a suprâhepatic abscess. Tenderness can sometimes be elicited at one or other of the following points: in the back, over the twelfth rib or lumbar region, and in front, over the costal margin or the uppễ abdomen. Occasionally there is a visible swelling and this occurs, according to Harley, most frequently anteriorly. Another local sign which dis well worth looking for is œdema of the overlying skin. Apart from these general symptoms and signs there are those which point to trouble either in the abdomen or in the chest.

\section{Abdominal Symptoms and Signs}

There may be abdominal distension, constip tion or diarrhœea, the latter especially in the presence of a pelvic abscess. With rupture of the subphrenic abscess into the liver or in the presen $\xi^{-}$ of cholangitis, jaundice may be evident. Persise tent and distressing hiccough has also been note\&. With suprahepatic abscesses the liver may be displaced downwards. The classical four zones alternating resonance and dullness, first described by Barlow (1845) are a textbook myth.

\section{Thoracic Symptoms and Signs}

While infra-hepatic abscesses give rise rô frequently to abdominal symptoms and sighs supra-hepatic suppuration tends to draw the clinician's attention to the thorax. Chest pain ha already been mentioned. A cough, frequent associated with purulent sputum, is not un common; even hæmoptysis does occur (Case NG. 5). On examination diminished respiratory move ment and dullness on percussion may be note⿳亠्ष巾, while on auscultation decreased air entry, a pleur rub or bronchial breathing are frequently foun $\Phi$. All these findings may be present in uncomplicated cases but will be even more obvious when intra thoracic complications have occurred. These symptoms and signs in the chest can overshadow the clinical picture to such a degree that the clinician may be totally unaware of the causat condition under the diaphragm.

\section{Radiological Signs}

The investigation which is most likely to establisid the diagnosis is the radiological examination. FaD this purpose postero-anterior and lateral films of the chest are essential. Lateral recumbent and penetrated basal films are also of great value, whife screening of the patient should never be omitted: The radiological findings are as follows:

\section{Pulmonary Findings}

Pleural reaction may be evidenced at first by $\underset{\otimes}{\stackrel{\overbrace{}}{\mathbb{Q}}}$ 
vague basal haziness, while obliteration of the costophrenic angle either in the p.a. or posteriorly in the lateral film means a pleural effusion. A larger effusion or empyema will give the typical appearance of fluid creeping up the chestwall.

Changes in the lung in the form of basal congestion, basal atelectasis or patchy areas of consolidation are often present. Harley found that there was frequently a triangular area of pulmonary collapse which was to be seen extending upwards and backwards in the paravertebral gutter towards the hilum. The mediastinum, however, in spite of the presence of atelectasis was often displaced to the opposite side because of the elevated diaphragm.

\section{Diaphragmatic Findings}

Elevation of the diaphragm is a frequent finding with supra-hepatic abscesses, but may also be seen with liver abscesses. The lateral film will often give information about the site of the abscess, as the most elevated portion of the diaphragm directly overlies it. On the left side a raised diaphragm is less constant because of absence of the liver and the relative mobility of the abdominal organs on that side. Screening will reveal loss of mobility. Neuhof and Schlossmann (1942), who made a special study of left-sided subphrenic abscesses, state that on this side paresis often precedes elevation. Other features which should be looked for are loss of definition, thickness and tenting of the diaphragm. These changes are due to the inflammatory reaction of the diaphragm, its pleura and the overlying lung. An immobile diaphragm with gas underneath it is frequently seen after laparotomy, but in these cases its leaf is sharply defined and thin, nor will the raised diaphragm often seen in uncomplicated amœbic liver abscesses be found to be thickened.

\section{Subphrenic Findings}

In approximately $30 \%$ of cases air with or without a fluid level is visible under the diaphragm (Ochsner and DeBakey 30\%, Harley $28 \%$, Windsor $32 \%$ ). The origin of the gas in subphrenic abscesses can be attributed to the following causes: perforation of a hollow viscus, air admitted at the time of laparotomy, or communication with a bronchus. The often-quoted gasforming organisms are probably never the source of it. For detection of gas under the diaphragm the penetrated basal film is of special value. Sometimes it is only visible in the lateral film. On the left side it may be difficult to distinguish a subphrenic collection of air from gaseous distension of the bowel or the gas bubble in the stomach. In this case the lateral recumbent radiograph may be of help, because air and fluid in the peritoneal cavity will shift laterally and downwards. A barium meal will also differentiate gas in an abscess from the stomach bubble and furthermore may show indentation or displacement of the stomach by a huge abscess. Downward displacement of the liver may be obvious in the penetrated film of the upper abdomen, but a similar finding is often found with intra-hepatic abscesses. Lilienthal (1937) and Sante (1940) recommend the induction of a pneumoperitoneum to assist in localizing and diagnosing an abscess in cases of doubt. Harley, however, considers that this practice is associated with a considerable risk of spread of the infection in the acute phase and advises its use only in the chronic cases.

\section{Diagnostic Aspiration of Subphrenic Abscess}

This diagnostic procedure is only mentioned to condemn it. If pus is obtained the pleura is liable to be infected and if the aspiration is negative, pus may still be present. It has therefore nothing to offer, but may add further complications. Aspiration of the pleura, however, is indicated in every case where an empyema is suspected. Therefore, after careful clinical and radiological examination, an exploratory operation has much more to commend it than diagnostic needling.

\section{Treatment}

In many instances infection of the subphrenic area probably resolves spontaneously, especially as antibiotics are nowadays used routinely in the postoperative period. In these cases the infection consists of a cellulitis, actual suppuration not yet having taken place. Wetterfors (1959) goes as far as to advise antibiotic treatment in the first instance and is content to wait for regression or absorption of the abscess. Only when this does not occur does he recommend surgical drainage. In his series conservative therapy with antibiotics gave a lower mortality than surgical treatment. On the other hand in Berens, Gray and Dockerty's (1953) series of 154 cases from the Mayo Clinic, chemotherapy did not lower the mortality. Thus of $8 \mathrm{I}$ patients treated with antibiotics, $24 . \mathrm{I} \%$ died, while in the 71 cases in which no chemotherapy was given the mortality was $21.1 \%$. Furthermore, Blades (1956) warns against the masking effects of antibiotics, these posing even greater diagnostic problems. As progression to suppuration is slow, conservative measures should be adopted, but once it has become established, drainage is indicated. Procrastination as in Case No. 2 is dangerous.

\section{Technique of Drainage}

In spite of the fact that the advantage of the extra-serous over the trans-serous drainage has 


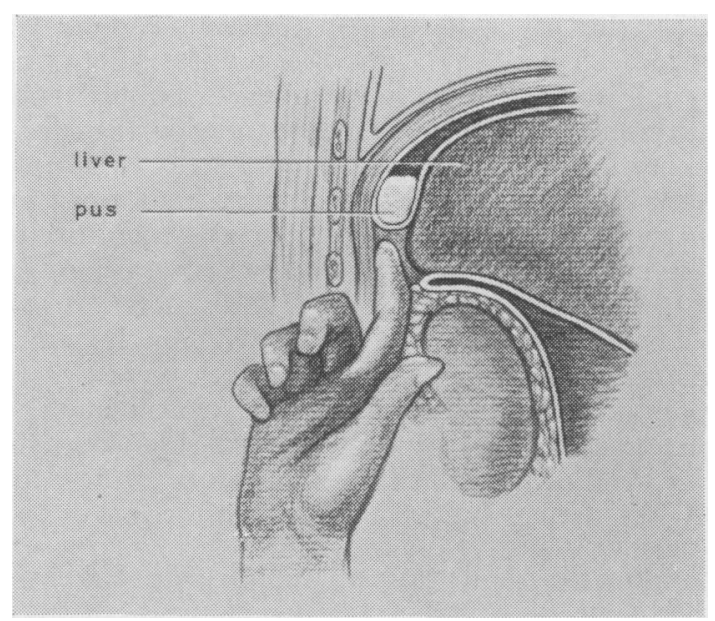

FIG. 12.-A posteriorly situated supra-hepatic abscess can be drained by the posterior extra-serous approach. The finger is inserted upwards through the bare area. (Modified from A. Ochsner and A. M. Graves, Ann. Surg., 98, 96r, 1933).

been repeatedly substantiated by various authors (Table I), the transpleural approach has again been recently recommended by some (Wooler, 1956; Boyd, 1959).

TABLE I

\begin{tabular}{|c|c|c|c|}
\hline \multicolumn{2}{|l|}{ Mortality } & $\begin{array}{l}\text { Extra- } \\
\text { serous }\end{array}$ & $\begin{array}{l}\text { Trans- } \\
\text { serous }\end{array}$ \\
\hline Ochsner and DeBakey (1938) & $\ldots$ & $\begin{array}{c}\% \\
20.8\end{array}$ & $\begin{array}{c}\% \\
35.8\end{array}$ \\
\hline Harley $(1949) \quad \ldots \quad \ldots$ & . & I I & 33 \\
\hline Windsor (1955) $\ldots$ & . & 13 & 25 \\
\hline Berens and others (1953) & . & 13 & 30.6 \\
\hline
\end{tabular}

Ochsner and Graves (1933) wrote: 'Intraper苂 toneal abscesses in which adhesions are preserat between the parietal peritoneum and the abscess cavity can be drained to all intents and purposes extra-serously, because if the incision is made through the area of adhesions no contamination of the uninvolved peritoneum will occur'.

This statement holds true now. Furthermore the majority of abscesses can be drained by the posterior extra-serous approach which they der scribe so well in their paper. The exception are those abscesses which either point anteriorly of which are situated in the lesser sac. These are best approached by the anterior extra-serou approach first described by Clairmont an Ranzi (1905).

\section{The Posterior Extra-serous Approach}

This was first described by Nather and Ochsne (1923) and by this approach all posteriorly situated abscesses can be drained without transo gressing a virgin pleural or peritoneal cavity en route to pus. This includes most of the suprahepatic abscesses as they present themselves mor often posteriorly and can therefore be reachea through the bare area (Fig. 12). An oblique incision is made in line with and over the tweft rib. This incision is carried down to the pesits osteum of the rib and the latter is resected sâb periosteally. An incision is then made transversl across the rib-bed, extending from, or at the leve of, the transverse process of the first lumbat vertebra laterally (Fig. 13). The pleura neves extends below this level and is thereby avoided The upper part of the peri-renal fascia will bo exposed and is displaced downwards with blunt finger dissection. The finger then explores the

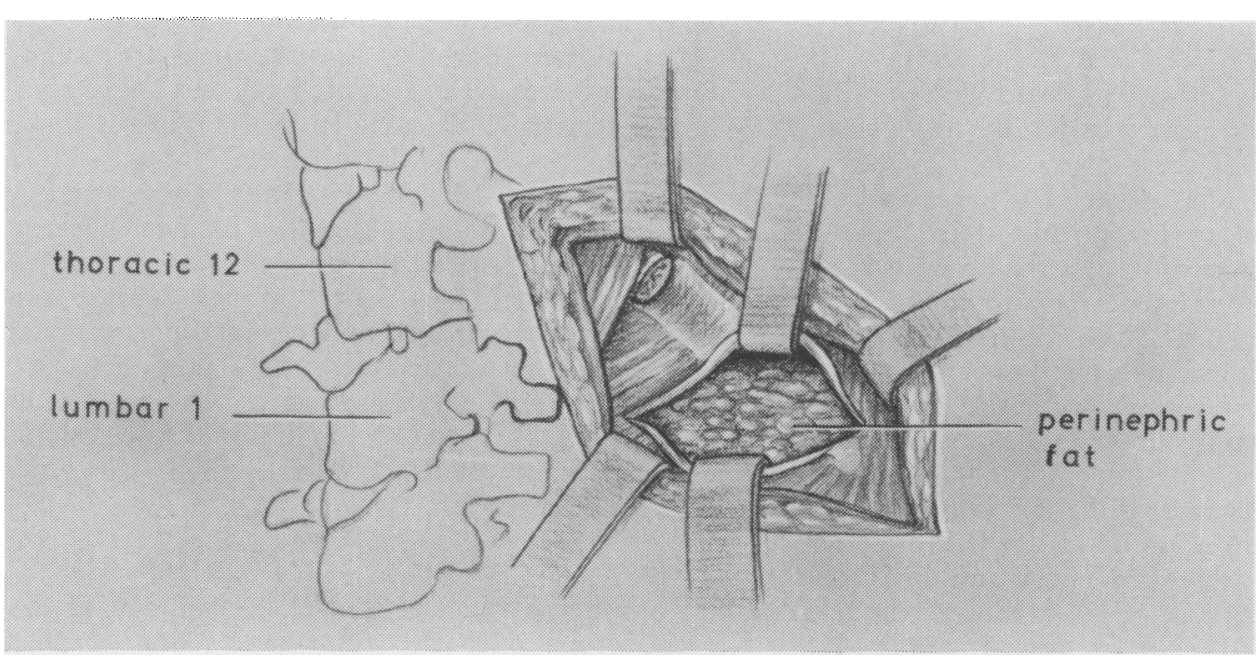

FIG. I3. - Thes posterior extraj serous ap. proach: Th@ skin is incise obliquely in lino with the 12th rib. After re section of this. rib, the pcrioso teum is incise transversely at the level of the transverse prow cess of the IS lumbar vertê bra, so as to avoid opening the pleura (Modified from A. Ochsner an $\Phi$ A. M. Graves Ann. Surg., 98्ठ 961, 1933). 
area behind the liver and feels for the typical œdematous, indurated area which surrounds the abscess. This is broken into and a large-bore tube is left in its cavity. The previously divided muscles and skin are closed around it and the tube securely fixed. A sample of the pus should always be sent for culture and the sensitivity of the organisms to the various antibiotics should be determined.

\section{The Anterior Extra-serous Approach (Clairmont and Ranzi, 1905)}

A high subcostal muscle cutting incision is made. On reaching the parietal peritoneum one dissects extra-peritoneally until the indurated area is felt, through which the abscess can then be opened. An abscess in the lesser sac is best approached by a paramedian incision.

\section{Postoperative Management}

In the immediate postoperative period the drainage tube is best connected to an underwaterseal bottle as this will save repeated dressings. Once the discharge has become less, the tube is allowed to drain into the dressing, but it must not be shortened until sinograms have shown that the abscess cavity has contracted down to a mere track. This process may take a very long time indeed. Premature shortening or removal of the tube will only lead to loculation of the abscess cavity.

Once adequate drainage has been instituted, the appropriate antibiotics are given and any anæmia corrected by blood transfusion. A constant watch should be maintained for further extension of the infection or development of intrathoracic complications. Repeated white cell counts and chest radiographs will give further information about the progress.

\section{Treatment of Thoracic Complications}

Any radiologically diagnosed effusions should be aspirated to ascertain their nature. Simple serous effusions can be left safely alone as they will absorb once the subphrenic abscess has been drained. An empyema, however, must be drained separately through the appropiate incision in the chest and is then treated entirely independently from the subphrenic condition. Thus a chronic empyema in neglected cases may call for decortication. Atelectasis of the lung should be treated by physiotherapy in the first instance, but if reexpansion does not take place within 24 hours, bronchoscopic suction should be carried out. In cases of peritoneo-pleuro-bronchial fistula a tracheotomy may be a life saving measure, as already mentioned. Finally it must be remembered that in a few cases the underlying infection may have been caused by amoebiasis or rarely by actinomycosis and in this case the appropriate chemotherapy is most essential.

\section{Summary}

In spite of the widespread use of antibiotics subphrenic abscesses are not uncommon, nor are the resultant complications. Their rather frequent insidious onset, the very paucity sometimes of clinical features and the frequency of added complications which tend to overshadow the underlying condition are stressed. The possibility of multiple space or bilateral space infection should always be kept in mind. Only early diagnosis and correct management will reduce in the future the high morbidity and mortality of this condition, thus extraserous in contrast to the transpleural approach is emphasized.

My thanks are due to Mr. Donald Barlow and Mr. J. R. Belcher, reports of whose patients I have included in this article. Permission was also granted by the Editor of the Annals of Surgery to publish in modified form Figs. 12 and 13 from the article by A. Ochsner and A. M. Graves, Ann. Surg., 98, 961, 1933. I wish also to thank Mr. Keith Ross for helpful criticism, Miss Graham, medical artist, and Mr. Stride, medical photographer, of Hillingdon Hospital, for the illustrations.

\section{REFERENCES}

Barlow, G. H. (1845): Perforation of the Stomach with Obscure Thoracic Symptoms, Lond. med. Gaz., $36,13$.

Barnard, H. L. (1908): An Address on Surgical Aspects of Subphrenic Abscess, Brit. med. F., i, 371 and 429.

Berens, J. J., Gray, H. K., and Dockerty, M. B. (1953): Subphrenic Abscess, Surg. Gynec. Obstet., 96, 463.

BLADES, B. (1956): Subphrenic Abscess (Editorial), Ibid., 103, 765.

Boyd, D. P. (1959): The Intrathoracic Complications of Subphrenic Abscess, f. thorac. Surg., 38, 77 I.

Clairmont, P., and Ranzi, E. (1905): Kasuistischer Beitrag zur operativen Behandlung des subphrenischen Abszesses, Wien. klin. Wschr., 18, 653 .

Gullickson, M. J., and Smith, R. G. (1956): Immediate Treatment of Bronchopleural-Peritoneal Fistula, a Complication of Subphrenic Abscess, $\mathcal{F}$. thorac. Surg., 31, 324 .

HaRLEY, H. R. S. (1949): Subphrenic Abscess, Thorax, 4, I.

(1955): 'Subphrenic Abscess'. Oxford: Blackwell. 
Lilienthal, H. (1937): Discussion of E. F. Lehman-The Place of Exploratory Operation in the Surgery of Sư phrenic Abscess, Ann. Surg., io6, 5 I4.

Mitchell, G. A. (G. (1940): 'The Spread of Acute Intraperitoneal Effusions, Brit. F. Surg., 28, 291.

Nather, C., and Ochisner, E. W. A. (1923): Retroperitoneal Oparation for Subphrenic Abscess, with the Report Gqf Two Cases, Surg. Gynec. Obstet., 37, 665 .

Neuhof, H., and Schlossmann, N. C. (1942): Left Subphrenic Abscess, Ibid., 75, 75 I.

Ochsner, A., and DeBakey, M. (1938): Subphrenic Abscass, Collective Review and Analysis of 3,608 Collected a Personal Cases, Int. Abstr. Surg., 66, 426.

- - and Graves, A. M. (1933): Subphrenic Abscess, an Analysis of 3,372 Collected and Personal Cases, Ann. Sur旁, 98, $96 \mathrm{r}$.

Overholt, R. H. (1931): Intraperitoneal Pressure, Arch. Surg., 22, 69 I.

——and Donches, J. C. (1935): Subphrenic Abscess, New Engl. F. Med., 213, 294.

Russell, T. H. (1929): Subphrenic Abscess, Ann. Surg., 90, 238.

Sante, L. R. (1940): Basal Exudates of Subphrenic Origin, Amer. F. Roentgenol., 44, 350.

Spalding, J. E. (I946): Fowler's Position, Lancet, i, 643.

Truesdale, P. E. (1933): Origin and Course of Infection in Subphrenic Abscess, Ann. Surg., 98, 846.

Wetterfors, J. (1959): Subphrenic Abscess, a Clinical Study of Ior Cases, Acta chir. scand., II7, 388.

Windsor, C. J. (1955): Subphrenic Abscess, Med. F. Aust., 42, igo.

WOOLER, G. H. (1956): Subphrenic Abscess, Thorax, II, 2 I I. 